\title{
NOMES PRÓPRIOS
}

\author{
John Searle*
}

Jean Rodrigues Siqueira*

Nomes próprios têm sentido? Frege ${ }^{80}$ argumenta que devem ter, pois, de outro modo, o que mais as declarações [statements] ${ }^{81}$ de identidade poderiam ser, ele se pergunta, se não declarações trivialmente analíticas? Como poderia, ele pergunta, uma declaração da forma $a=b$, se verdadeira, diferir em valor cognitivo de $a=a$ ? Sua resposta é que, embora "a" e "b" tenham o mesmo referente, elas têm ou podem ter sentidos diferentes, caso em que a declaração é verdadeira, mas não analiticamente verdadeira. Mas essa solução parece mais apropriada quando "a" e "b" são descrições definidas não sinônimas, ou quando uma é uma descrição definida e a outra um nome próprio, do que quando ambas são nomes próprios. Considere, por exemplo, declarações feitas com as sentenças a seguir:

(a) “Túlio=Túlio" é analítica.

Mas,

(b) "Túlio=Cícero" é sintética?

Se sim, então cada nome deve ter um sentido diferente, o que à primeira vista parece mais implausível, pois ordinariamente nós não pensamos que os nomes próprios têm sentido da mesma maneira que os predicados; por exemplo, nós não damos definições dos nomes. Mas é claro que (b) nos dá informação não transmitida por (a). Mas essa informação diz respeito às palavras? A declaração não é a respeito de palavras.

Por ora, vamos considerar a concepção de que (b), assim como (a), é analítica. Uma declaração é analítica se e somente se ela é verdadeira apenas em virtude das regras linguísticas, sem qualquer recurso à investigação empírica. As regras linguísticas para usar o nome "Cicero" e as regras linguísticas para usar o nome "Túlio" são tais que ambos os nomes referem o mesmo objeto idêntico sem descrevê-lo; assim, parece que a verdade da identidade pode ser estabelecida unicamente mediante recurso a essas regras e que, então, a declaração é analítica. O sentido em que

Texto originalmente publicado em 1958 no periódico Mind, New Series, vol. 67, número 266,pp. 166-173.

. John Searle (1932-) é um filósofo estadunidense, nascido em Denver, Colorado. Atualmente é professor da Universidade de Berkeley, na Califórnia.

** Doutorando em Filosofia pela Universidade Presbiteriana Mackenzie. Mestre em Filosofia pela PUC-SP. Professor do Curso de Filosofia do Centro Universitário Assunção - UNIFAI.

${ }^{80}$ Translations from the Philosophical Writings of GottlobFrege, editado por Geach e Black, pp. 56s.[N.do A.]

${ }^{81}$ Alguns termos do original em inglês, cuja versão para o português feita aqui poderia divergir de opções linguísticas comumente presentes em outras traduções de textos sobre o tema, aparecerão, em sua primeira ocorrência, indicados em caracteres itálicos e entre colchetes no corpo desta tradução. 
a declaração é informativa é o sentido em que qualquer declaração analítica é informativa; ela ilustra ou exemplifica certos fatos contingentes acerca das palavras, embora, é claro, ela não descreva esses fatos. Segundo essa explicação, a diferença acima entre (a) e (b) não é tão grande quanto poderia parecer inicialmente. Ambas são analiticamente verdadeiras, e ambas ilustram fatos contingentes acerca do nosso uso de símbolos. Alguns filósofos afirmam que (a) é fundamentalmente diferente de (b) na medida em que a declaração fazendo uso dessa forma será verdadeira para qualquer substituição arbitrária dos símbolos que tomar o lugar de "Túlio" 82 . Isso, eu gostaria de argumentar, não é o caso. $\mathrm{O}$ fato de que as mesmas marcas refiram o mesmo objeto em duas ocasiões diferentes de seu uso é algo conveniente, mas contingente, e, de fato, podemos facilmente imaginar situações onde esse não seria o caso. Suponha, por exemplo, que temos uma linguagem onde as regras para usar símbolos não estão correlacionadas apenas a uma palavra-tipo [type-word], mas com a ordem de aparição de suas ocorrências [token] no discurso. Alguns códigos são dessa maneira. Suponha que a primeira vez que um objeto é referido em nosso discurso seja por meio de " $x$ ", a segunda, por meio de " $y$ ", etc. Para qualquer um que conheça esse código, "x=y" é trivialmente analítica, mas " $\mathrm{x}=\mathrm{x}$ " não tem sentido. Esse exemplo ilustra a similaridade entre (a) e (b) acima; ambas são analíticas e ambas nos dão informação, embora cada uma nos dê informação diferente acerca do uso das palavras. A verdade das declarações Túlio=Túlio e Túlio=Cícero decorre das regras linguísticas. Mas o fato de que as palavras "Túlio=Túlio" sejam usadas para expressar essa identidade é um fato tão contingente, embora mais universalmente convencional, quanto o fato de que as palavras "Túlio=Cícero" são usadas para expressar a identidade do mesmo objeto.

Essa análise permite-nos ver de que maneira tanto (a) como (b) poderiam ser usadas para constituir declarações analíticas e como poderíamos, em tais circunstâncias, adquirir informações diferentes acerca delas, sem nos forçar a seguir alguma das soluções propostas por Frege, isto é, a de que as duas proposições são, em algum sentido, acerca de palavras (Begriffschrtift), ou sua visão revisada de que os termos têm o mesmo referente, mas sentidos diferentes (SinnundBedeutung). Mas, embora essa análise nos permita ver de que maneira uma sentença como (b) poderia ser usada para fazer uma declaração analítica, não se segue que ela não poderia também ser usada para fazer uma declaração sintética. E, de fato, algumas declarações de identidade usando dois nomes próprios são claramente sintéticas; pessoas que argumentam que Shakespeare era Bacon não estão propondo uma tese acerca da linguagem. No que segue, espero examinar a conexão entre os nomes próprios e

\footnotetext{
${ }^{82}$ W. V. Quine, From a Logical Point of View, especialmente o cap. 2.[N.do A.]
} 
seus referentes, de maneira a mostrar como ambos os tipos de declarações de identidade são possíveis e, assim, mostrar em que sentido um nome próprio tem sentido.

Até agora estive considerando a concepção de que as regras que governam o uso dos nomes próprios são tais que eles são usados para referir e não para descrever um objeto particular, que eles têm referência, mas não têm sentido. Mas agora vamos nos perguntar de que maneira nos tornamos capazes de referir um objeto particular usando seu nome. Como, por exemplo, aprendemos e ensinamos o uso dos nomes próprios? Isso parece bastante simples - nós identificamos o objeto e, assumindo que nosso estudante compreende as convenções gerais governando os nomes próprios, explicamos que essa palavra é o nome do objeto. Mas a menos que nosso estudante já conheça outro nome próprio do objeto, nós podemos apenas identificar o objeto (a necessidade preliminar para ensinar o nome) por ostensão ou descrição; e, em ambos os casos, identificamos o objeto em virtude de algumas de suas características. Assim, parece agora que as regras para os nomes próprios devem estar, de algum modo, logicamente ligadas às características particulares dos objetos, de tal maneira que o nome tenha um sentido tanto quanto uma referência; na verdade, parece que ele não poderia ter uma referência a menos que tivesse um sentido, pois como estaria correlacionado ao objeto a menos que fosse desse modo?

Suponha que alguém respondesse assim a esse argumento: "As características encontradas no ensino do nome não são as regras para usar o nome; elas são apenas recursos pedagógicos empregados no ensino do nome a alguém que não sabe como usá-lo. Tão logo nosso estudante tenha identificado o objeto ao qual o nome se aplica, ele pode esquecer ou ignorar essas várias descrições por meio das quais identificou o objeto, pois elas não são parte do sentido do nome; o nome não tem um sentido. Suponha, por exemplo, que ensinemos o nome 'Aristóteles' explicando que ele se refere ao filósofo grego nascido em Estagira, e suponha que nosso estudante continue a usar o nome corretamente, que ele reúna mais informação sobre Aristóteles, e por aí vai. Vamos supor que mais tarde se descubra Aristóteles não nasceu em Estagira, mas em Tebas. Ora, não diremos agora que o significado do nome mudou, ou que Aristóteles na verdade sequer existiu. Em suma, explicar o uso do nome 'Aristóteles' citando características do objeto não é dar as regras para o uso do nome, pois regras não contêm qualquer conteúdo descritivo. Elas simplesmente correlacionam o nome ao objeto independentemente de quaisquer descrições acerca dele".

Mas esse argumento é convincente? Suponha que a maioria ou todo nosso conhecimento atual de fato sobre Aristóteles seja provado como não sendo verdadeiro acerca de ninguém, ou verdadeiro a respeito de pessoas vivendo em países distintos ou em diferentes países. Não diríamos, 
por essa razão, que Aristóteles nem existiu, e que o nome, embora tenha um sentido convencional, não refere ninguém? Pela explicação acima, se alguém dissesse que Aristóteles não existiu, isso seria apenas outra maneira de dizer que "Aristóteles" não denotava nenhum objeto, nada mais; mas se alguém dissesse que Aristóteles não existiu, poderia querer significar muito mais do que simplesmente que o nome não denotava ninguém ${ }^{83}$. Se, por exemplo, nós desafiássemos sua declaração apontando um homem chamado "Aristóteles” que viveu em Hoboken em 1903, ele não consideraria isso como uma contestação relevante. Nós dizemos que Cerberus e Zeus não existiram, sem querer dizer com isso que nenhum objeto jamais teve esses nomes, mas apenas que certas espécies (descrições) de objetos nunca existiram, mas tiveram esses nomes. Assim, parece agora que os nomes próprios necessariamente têm um sentido, mas têm uma referência apenas contingentemente. Eles começam a parecer cada vez mais como abreviações e, talvez, descrições vagas.

Vamos resumir as duas concepções conflitantes sob consideração: a primeira afirma que os nomes próprios têm essencialmente uma referência, mas não um sentido - nomes próprios denotam, mas não conotam; a segunda afirma que eles têm essencialmente um sentido e apenas contingentemente uma referência - referem apenas sob a condição de que um, e apenas um, objeto satisfaça seu sentido.

Essas duas concepções são caminhos que conduzem a sistemas metafísicos respeitáveis e divergentes. A primeira conduz a objetos últimos da referência, às substâncias dos escolásticos e aos Gegenstände do Tractatus. A segunda conduz à identidade dos indiscerníveis, às variáveis de quantificação como os únicos termos referenciais da linguagem. A estrutura sujeito-predicado da linguagem sugere que a primeira deve estar certa, mas a maneira como usamos e ensinamos o uso dos nomes próprios sugere que ela não pode estar certa: um problema filosófico.

Vamos começar examinando a segunda. Se o que se afirma é que todo nome próprio tem um sentido, tem de ser legítimo perguntar, acerca de qualquer nome, “Qual é seu sentido?”. Se o que se afirma é que o nome próprio é uma espécie de descrição abreviada, então deveríamos ser capazes de apresentar a descrição no lugar do nome próprio. Mas como faríamos isso? Se tentarmos apresentar como sentido de um nome próprio uma descrição completa do objeto, consequências estranhas parecem se seguir, por exemplo, que qualquer declaração verdadeira acerca do objeto usando o nome como sujeito seria analítica, e as falsas seriam contraditórias; que o significado do nome (e talvez a identidade do objeto) mudaria toda vez que ocorresse qualquer mudança no objeto; que o

\footnotetext{
${ }^{83}$ Cf. Wittgenstein, Philosophical Investigations, parágrafo 79.[N.do A.]
} 
nome teria significados diferentes para pessoas diferentes, etc. Assim, suponha que perguntemos quais são as condições necessárias e suficientes para a aplicação de um nome particular a um objeto particular. Suponha, para fins de argumentação, que tenhamos maneiras independentes de situar esse objeto; quais seriam as condições para, por exemplo, dizermos "Este é Aristóteles"? À primeira vista, essas condições parecem simplesmente ser a de que o objeto deve ser idêntico ao objeto originalmente batizado por esse nome e, então, o sentido do nome consistiria em uma declaração ou conjunto de declarações afirmando as características que constituiriam sua identidade. O sentido de "Este é Aristóteles" poderia ser "Este objeto é espaço-temporalmente contínuo com um objeto originalmente nomeado 'Aristóteles"'. Mas isso não bastaria, pois, conforme já foi sugerido, a força de "Aristóteles" é maior do que a força de "idêntico ao objeto nomeado "Aristóteles", pois não seria qualquer objeto nomeado "Aristóteles" que serviria. "Aristóteles" aqui refere um objeto particular nomeado "Aristóteles" e não qualquer um. "Nomeado "Aristóteles"” é um termo universal, mas “Aristóteles" é um nome próprio, assim "Este é nomeado Aristóteles” é, no melhor dos casos, condição necessária, mas não suficiente, para a verdade de "Este é Aristóteles". De maneira breve e trivial, não é sua identidade com qualquer objeto nomeado "Aristóteles", mas antes sua identidade com Aristóteles o que constitui as condições necessárias e suficientes para a verdade de "Este é Aristóteles".

Talvez possamos resolver o conflito entre as duas visões da natureza dos nomes próprios perguntando qual é a função única dos nomes próprios em nossa linguagem. Para começar, na maior parte das vezes eles referem ou se propõem a referir objetos particulares; mas é claro que outras expressões, descrições definidas e demonstrativos também desempenham essa função. Qual é, então, a diferença entre os nomes próprios e as outras expressões singulares que referem? Diferentemente dos demonstrativos, um nome próprio refere sem pressupor qualquer cenário ou quaisquer condições contextuais especiais acerca da enunciação [utterance] da expressão. Diferentemente das descrições definidas, em geral eles não especificam qualquer característica dos objetos que referem. "Scott" refere o mesmo objeto que "o autor de Waverley", mas "Scott" não especifica nenhuma de suas características, ao passo que "o autor de Waverley" refere somente em virtude do fato de especificar uma característica. Examinemos essa diferença de maneira mais próxima. Seguindo Strawson ${ }^{84}$, podemos dizer que os usos tanto dos nomes próprios como das descrições definidas para referir pressupõem a existência de um, e apenas um, objeto referido. Mas na medida em que, em geral, o nome próprio não especifica quaisquer características do objeto

\footnotetext{
${ }^{84}$ “On Referring”, Mind, 1950.[N.do A.]
} 
referido, como então ele faz a referência? De que maneira a conexão entre um nome e o objeto é estabelecida? A esta, que parece ser a questão crucial, eu quero responder dizendo que embora os nomes próprios normalmente não afirmem ou especifiquem quaisquer características, seus usos para referir, não obstante, pressupõem que o objeto que eles se propõem a referir possui certas características. Mas quais? Suponha que solicitemos àqueles que usam o nome "Aristóteles" que declarem o que consideram ser certos fatos essenciais e estabelecidos acerca dele. Suas respostas serão um conjunto de declarações descritivas que referem uma única coisa. Agora, o que estou argumentando é que a força descritiva de "este é Aristóteles" é afirmar que um número suficiente, mas não especificado desses enunciados é verdadeiro acerca desse objeto. Portanto, os usos de "Aristóteles" pressupõem a existência de um objeto acerca do qual um número suficiente, mas não especificado dessas declarações é verdadeiro. Usar um nome próprio para referir é pressupor a verdade de certas declarações descritivas que referem algo único, mas sem normalmente afirmar essas declarações ou mesmo indicar quais exatamente estão pressupostas. E aqui reside a maioria das dificuldades. A questão acerca do que constitui os critérios para “Aristóteles" geralmente é deixada em aberto, na verdade, ela de fato raramente aparece, e quando isso acontece, somos nós, os que usam o nome, que decidimos, de maneira mais ou menos arbitrária, quais serão esses critérios. Se, por exemplo, das características de Aristóteles assentadas como verdadeiras, metade delas fossem descobertas como sendo verdadeiras de um homem e metade de outro, qual deles diríamos que era Aristóteles? Nenhum? Não teríamos como decidir a questão com antecedência.

Mas essa imprecisão a respeito de que características exatamente constituem as condições necessárias e suficientes para a aplicação de um nome próprio é um mero acidente, um produto de um desmazelo linguístico? Ou será que ela deriva das funções que os nomes próprios desempenham para nós? Perguntar pelos critérios para a aplicação do nome "Aristóteles" é perguntar no modo formal o que Aristóteles é; é perguntar por um conjunto de critérios de identidade para o objeto Aristóteles. "O que é Aristóteles?" e "Quais são os critérios para aplicar o nome Aristóteles?" perguntam a mesma questão, a primeira no modo material e a última no modo formal do discurso. Assim, se ao usar o nome concordássemos com antecedência acerca de precisamente quais características constituem a identidade de Aristóteles, nossas regras para usar o nome seriam precisas. Mas essa precisão seria atingida somente ao preço de implicar alguns predicados específicos para qualquer uso referencial do nome. $\mathrm{Na}$ verdade, o próprio nome se tornaria supérfluo, pois ele se tornaria logicamente equivalente a esse conjunto de descrições. Mas se esse fosse o caso, nós estaríamos em posição de ser capazes de referir um objeto somente ao descrevê-lo. 
E, de fato, isso é exatamente o que a instituição dos nomes próprios nos permite evitar e o que distingue os nomes próprios das descrições. Se o critério para os nomes próprios fosse bastante rígido em todos os casos, então um nome próprio nada mais seria do que uma abreviação para esses critérios, um nome próprio funcionaria exatamente como uma descrição definida elaborada. Mas a peculiaridade e imensa conveniência pragmática dos nomes próprios em nossa linguagem residem precisamente no fato de que eles nos possibilitam referir publicamente a objetos sem sermos forçados a levantar questões a respeito de exatamente que características descritivas constituem sua identidade. Eles funcionam não como descrições, mas como cabides nos quais penduramos as descrições. Assim, a frouxidão dos critérios para os nomes próprios é uma condição necessária para separar na linguagem a função de referir da função de descrever.

Para colocar o mesmo ponto de maneira diferente, suponha que perguntemos: "Afinal, por que temos nomes próprios?” Para referir indivíduos, obviamente. "Sim, mas as descrições poderiam fazer isso para nós". Mas apenas ao preço de ter que especificar condições de identidade toda vez que a referência é feita. Suponha que concordemos em abandonar "Aristóteles” e usar, digamos, “o professor de Alexandre", então é uma verdade necessária que o homem referido é o professor de Alexandre - mas é um fato contingente o de que Aristóteles tenha vindo a se dedicar ao ensino (embora eu esteja sugerindo que é um fato necessário que Aristóteles tenha a soma lógica, uma disjunção inclusiva, de propriedades comumente atribuídas a ele: qualquer indivíduo que não tivesse pelo menos algumas dessas propriedades não poderia ser Aristóteles).

É claro que não se deveria pensar que o único tipo de frouxidão dos critérios de identidade para indivíduos é esse que tenho descrito como peculiar aos nomes próprios. Usos das descrições definidas para referir podem levantar problemas de diversos tipos a respeito da identidade. Isso é especialmente verdadeiro de descrições definidas no pretérito. "Esse é o homem que ensinou Alexandre" pode, por exemplo, ser tomada como implicando que esse tipo de objeto é espaçotemporalmente contínuo com o homem ensinando Alexandre em outro ponto do espaço-tempo; mas alguém também poderia argumentar que a continuidade espaço-temporal desse homem é uma característica contingente e não um critério de identidade. E a natureza lógica da conexão de tais características com a identidade do homem pode novamente ser frouxa e, de antemão, de disputa indecidível. Mas essa é justamente outra dimensão da frouxidão diferente da que citei como frouxidão dos critérios para aplicar nomes próprios, e ela não afeta a distinção em pauta entre as descrições definidas e os nomes próprios, a saber, de que as descrições definidas referem somente em virtude do fato de que os critérios não são frouxos nesse sentido, pois elas referem quando nos 
dizem o que o objeto é. Mas nomes próprios referem sem sequer levantar a questão a respeito do que o objeto é.

Estamos agora em posição de explicar como é que "Aristóteles" tem uma referência mas não descreve, e, contudo, a declaração "Aristóteles nunca existiu" diz mais do que dizer que "Aristóteles" nunca foi utilizado para referir qualquer objeto. A declaração afirma que um número suficiente de pressuposições convencionais, declarações descritivas, de usos de "Aristóteles" para referir, é falso. Precisamente qual declaração afirmada é falsa ainda não é claro, pois quais condições precisamente constituem o critério para aplicar "Aristóteles" não foram estabelecidas de antemão pela linguagem.

Podemos agora resolver nosso paradoxo: nomes próprios têm sentido? Se a pergunta quer saber se nomes próprios são usados para descrever ou especificar características de objetos que eles referem, a resposta é "não". Mas se ela quer saber se nomes próprios estão logicamente conectados a características do objeto que referem, a resposta é "sim, de uma maneira um tanto frouxa". (Isso mostra em parte a pobreza de uma abordagem sentido-referência, denotação-conotação, na teoria do significado).

Poderíamos clarificar esses pontos ao comparar nomes próprios paradigmáticos com nomes próprios degenerados, como “O Banco da Inglaterra”. Nestes, parece, que o sentido é dado tão claramente quanto em uma descrição definida; as pressuposições, por assim dizer, emergem à superfície. E um nome próprio pode adquirir um uso descritivo rígido sem ter a forma verbal de uma descrição: para aqueles que creem, Deus é, por definição, justo, onipotente, onisciente, etc. A forma, é claro, pode nos enganar; o Sacro Império Romano não era nem sacro, nem romano, etc., mas era, não obstante, o Sacro Império Romano. Pode ser que seja convencional chamar apenas garotas de "Marta", mas se eu desse o nome de "Marta" ao meu filho, isso poderia causar engano, mas não seria uma mentira.

Agora, reconsidere nossa identidade original, "Túlio=Cícero". Uma declaração feita usando essa sentença seria, eu sugiro, analítica para a maioria das pessoas; as mesmas pressuposições descritivas estão associadas a cada nome. Mas, é claro, se as pressuposições descritivas fossem diferentes ela poderia ser usada para fazer uma declaração sintética; poderia até promover uma descoberta histórica de grande importância. 